\title{
"NADIE ESCUCHÓ LOS LLANTOS": FÚTBOL, CRÓNICA Y REPRESIÓN EN LA NOVELA NEGRA HISPÁNICA DEL XXI
}

\author{
DaVId García CAMES \\ Universidad de Salamanca \\ garciacames@gmail.com
}

RESUMEN: El fútbol está hecho de héroes pero también de mafias, apuestas, corrupción y violencia. El género negro se ha acercado de forma reiterada a todo aquello que rodea al fútbol como tema y fuente de inspiración. Tras situar algunos de los principales antecedentes, este artículo traza en primer término una panorámica sobre fútbol y novela negra en la literatura hispánica del siglo xxI. Más adelante, se analiza el papel que desempeña el fútbol como motivo desde el que abordar los mecanismos de funcionamiento del poder en las novelas Todo está perdonado (2011), del español Rafael Reig, y La pena máxima (2014), del peruano Santiago Roncagliolo. La fusión de narrativa policial y crónica futbolística se pone al servicio de la voluntad de denuncia que mueve a estos autores. El uso literario del fútbol actúa en ambos como puerta de entrada que permite construir un discurso autónomo sobre la represión en determinados periodos históricos.

PalABRAS CLAVE: fútbol y literatura; novela negra; Rafael Reig; Santiago Roncagliolo

ABSTRACT: Football is made of heroes but is also made of gangs, gambling, corruption and violence. Crime fiction has used everything that surrounds football as a theme and inspiration. This paper examines the presence of football in Hispanic crime novels during the 21st century. Specifically, the article analyses 
the role of football as a background employed to describe the mechanisms of power in the novels Todo está perdonado (2011), by the Spanish Rafael Reig, and La pena máxima (2014), by the Peruvian Santiago Roncagliolo. The fusion of football chronicle and hard-boiled reveals the social criticism of these novelists. The literary use of football provides a gateway to construct an autonomous discourse on repression during certain historical periods.

Keywords: Football and Literature; Crime Fiction; Rafael Reig; Santiago Roncagliolo

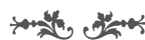

\section{FÚtbol y NOVELA NEGRA}

No hay score ni cuadros ni partidos. Los estadios ya son demoliciones que se caen a pedazos. Hoy todo pasa en la televisión y en la radio. La falsa excitación de los locutores ¿nunca lo llevó a maliciar que todo es patraña? El último partido de fútbol se jugó en esta capital el día 24 de junio del 37.

Jorge Luis Borges y Adolfo Bioy Casares, Esse est percipi

A pocos metros del estadio del Chelsea, Stamford Bridge, se encuentra el cementerio de Brompton. Cada día de partido, los aficionados caminan entre las tumbas en dirección al campo donde empieza a ocupar su lugar en el palco el magnate y presidente Román Abramóvich. Los hooligans, vestidos con sus camisetas azules, entonan los cánticos de guerra mientras el estadio continúa proyectando su sombra sobre este camposanto del siglo XIX. Entre la vorágine de hinchas, al lado de las lápidas, bajo la mirada omnipotente de algún oligarca y sus secuaces, un asesinato pasaría completamente desapercibido, tal y como ocurre en la película Eastern Promises (2007), de David Cronemberg. La muerte convive con el fútbol y el fútbol, al mismo tiempo, puede ser una perfecta puerta de entrada para el escritor que pretende reflejar en su obra algunas de las principales dinámicas de nuestro tiempo: "Lo que se juega en la comprensión del fútbol ayuda a hacerse cargo de la época en que se está, para bien o para mal de los diagnósticos" (Verdú 2010: 5). La violencia latente en la sociedad se materializa en el deporte tanto mediante los grandes organismos corruptos que controlan su funcionamiento ${ }^{1}$ como a través de las bandas criminales que campan a sus

\footnotetext{
${ }^{1}$ Sobre los escándalos de corrupción en la FIFA pueden leerse, casi como una crónica negra de los hechos, los libros del periodista escocés Andrew Jennings: Foul! The Secret World of FIFA: Bribes, Vote-Rigging and Ticket Scandals (2006) y Omertà: Sepp Blatter's FIFA Organised Crime Family (2014). En 2015 se publicó en España el libro del alemán Thomas Kistner: FIFA Mafia. La historia de la organización deportiva más grande del mundo. También recomendamos el libro, originalmente una tesis de doctorado, del periodista y académico canadiense Declan Hill: Juego sucio. Fútbol y crimen organizado (2010).
} 
anchas en los estadios: "El fútbol pone en contacto con la inocencia del buscador de héroes, pero también enciende hogueras" (Villoro 2006: 24). La ceremonia del fútbol convoca ritos que nos conectan con algunas de las experiencias básicas de nuestra infancia sin dejar de lado la presencia de la muerte. Después de todo, quizá no tan solo el estadio de Stamford Bridge cubra hoy en día con su sombra sobre los mármoles de un cementerio.

El fútbol, como síntoma y como la representación más acabada del espectáculo de masas global, no ha podido dejar de ejercer una fascinación cada vez mayor entre los escritores de novela negra. Dentro de la voluntad de denuncia que mueve a muchos de sus autores, el balompié representa un microcosmos desde el que abordar algunos temas recurrentes del género, como los intereses económicos, la violencia, el poder político, las mafias, las apuestas y, en definitiva, todas aquellas circunstancias que rodean a este deporte y que ponen de manifiesto el gigantismo del fenómeno y "la elefantiasis de la criatura" (Vázquez Montalbán 2005: 27). El fútbol permea todos las capas del tejido social, propiciando que pueda hablarse en determinadas ocasiones de una futbolización de nuestra existencia cotidiana, tal y como apunta el sociólogo argentino Pablo Alabarces: "Asistimos a una suerte de deportivización de la agenda cotidiana (que en la mayoría de los casos se naturaliza como futbolización), según la cual todo debe ser discutido en términos deportivos" (2000: 13). ${ }^{2}$ Los escritores del género negro, en su impulso de abarcar el rostro poliédrico de las sociedades contemporáneas, también han prestado su oído a esa "cháchara deportiva" mediante la cual el fútbol pasa a invadir nuestras conversaciones, tanto desde el punto de vista del hincha que consagra a sus héroes como del aficionado que denuncia las corruptelas y el carácter mercantil del deporte: "La cháchara deportiva, nacida como elevación a la enésima potencia de ese derroche inicial (y razonado) que era el juego deportivo, es la magnificación del Derroche, y por tanto el punto máximo del Consumo" (Eco 1996: 186-187). ${ }^{3}$

\footnotetext{
${ }^{2}$ La obra de Pablo Alabarces se considera una de las más válidas aproximaciones sociológicas al fenómeno futbolístico. Durante décadas de investigación, sus trabajos abordan temas como la violencia, la masculinidad o la formación de la identidad nacional en relación al fútbol. Además de numerosos artículos, destacamos los siguientes libros: Fútbol y Patria. El fútbol y las narrativas de la Nación en la Argentina (2002), Crónicas del aguante. Fútbol, violencia y política (2004), Héroes, machos y patriotas. El fútbol entre la violencia y los medios (2014) y, como compilador, los volúmenes Peligro de gol. Estudios sobre deporte y sociedad en América Latina (2000), Futbologías. Fútbol, identidad y violencia en América Latina (2003) e Hinchadas (2005).

${ }^{3}$ Camilo José Cela ya presentaba en 1963, dentro de su libro Once cuentos de fútbol, una sátira del fútbol como actividad meramente comercial. En la primera sección del libro, titulada "La lonja", ofrecía el retrato de representantes de futbolistas que actuaban como verdaderos tratantes de ganado, fichando a ídolos africanos a cualquier precio, embalsamando a jugadores y dopando sin remsión a sus "carneros de oro". Sobre la lógica de mercado del fútbol pueden consultarse las páginas que Manuel Vázquez Montalbán dedicó a la producción de ídolos en Fútbol. Una religión en busca de un Dios. Acerca del balompié y su papel en la economía global pueden leerse Franklin Foer: El mundo en un balón: La globalización a través del fútbol (2004) y Simon Kuper y Stefan Szymanski: El futbol es así (Soccernomics): Una explicación económica sobre los mitos y verdades del deporte (2010). Sobre fútbol y marketing destacamos Jaime Rivera y Víctor Molero: Marketing y fútbol. El mercado de las pasiones (2012), y Ángel Agudo y Francisco Toyos: Marketing del fútbol (2003).
} 
Algunos de los grandes iconos de la novela negra se han acercado a este magma que envuelve al acontecimiento futbolístico. El último que ha venido a sumarse a la lista es Philip Kerr, quien en Mercado de invierno, publicada en España en 2015, elabora una trama criminal en torno al asesinato de un director deportivo llamado João Zarco, personaje que actúa como trasunto de José Mourinho, técnico del Chelsea. La novela está protagonizada por Scott Manson, segundo entrenador del equipo e investigador ocasional, un personaje que Philip Kerr tiene la intención de desarrollar en una saga con dos nuevos libros acerca de la corrupción en el mundo del fútbol: Hand of God y False nine. ${ }^{4}$ Como pone de manifiesto el caso del escritor escocés, los escritores de género negro emplean el fútbol como objeto principal de la trama o bien como un marco cronológico y simbólico que envuelve los acontecimientos. Ya en 1995 Henning Mankell recurrió al Mundial de Estados Unidos, celebrado un año antes, como telón de fondo de su libro La falsa pista, novela de la saga de Kurt Wallander en la que el fútbol desempeña un papel tangencial. El italiano Giorgio Faletti abordó, a través de la relación entre un padre y su hijo, el tema de las apuestas en el fútbol italiano dentro de Tres actos y dos partes (2011). Por último, podríamos destacar el retrato de las miserias del fútbol que elabora Petros Márkaris en Defensa cerrada (1998), donde la investigación del comisario Kostas Jaritos sobre el asesinato de un árbitro saca a la luz los auténticos intereses que mueven a los presidentes de los clubs. Más recientemente, el escritor griego evocó el Mundial de Sudáfrica en su libro Con el agua al cuello (2010), donde los conocidos y familiares de Jaritos contemplan la victoria de España como un triunfo de los humillados países del sur de Europa frente a los representantes de los poderes económicos, personificados en la selección holandesa: "No queremos que el Fondo Monetario Internacional gane el Mundial, señor comisario [...] Nos lo han quitado todo, no se quedarán también con el Mundial" (Márkaris 2010: 224-225). El gol de Iniesta es visto entonces como una fraternal explosión de resentimiento y entusiasmo de los oprimidos de la "troika", una victoria capaz de convertir a Katerina, la hija del comisario, en una "fanática fundamentalista": "¡Andrés, eres un dios! -vocifera mi hija" (Márkaris 2010: 240).

Si nos centramos en la literatura hispánica, la novela El delantero centro fue asesinado al atardecer (1988), de Manuel Vázquez Montalbán, marcó un punto de inflexión en cuanto al tratamiento literario del fútbol en el género negro. ${ }^{5}$ Prota-

\footnotetext{
${ }^{4}$ La saga de Kerr encuentra un curioso precedente en el ciclo protagonizado por James Hazell, personaje creado por el escritor Gordon Williams y el entrenador de fútbol inglés Terry Venables. Si bien el fútbol no desempeña un papel destacado como en el libro de Kerr, el hecho de estar escrito a medias por un técnico hace que incorpore algunos temas del mundo del deporte. El personaje fue llevado a la televisión en una serie emitida entre 1978 y 1979. Tres de las novelas fueron traducidas al castellano por la editorial Destino en 1985, cuando Venables era entrenador del FC Barcelona: Me llamo James Hazell, Hazell y el bromista peligroso y Hazell y el timo de las tres cartas. La colaboración entre estos dos autores ya se había traducido antes en una novela sobre fútbol titulada They Used to Play on Grass (1972).

${ }^{5}$ El libro rinde homenaje en su título a la pieza teatral El centroforward murió al amanecer, escrita por el dramaturgo argentino Agustín Cuzzani en 1955. Esta obra inserta el fútbol en una trama surrealista con préstamos del género negro pero también del fantástico. El argumento relata la venta de una estrella del fútbol, Arístides "Cacho" Garibaldi, a un millonario que colecciona hom-
} 
gonizada por el detective Pepe Carvalho, el libro relata, a través de dos tramas paralelas, la decadencia de un antiguo jugador del Barcelona, Alberto Palacín; junto con la llegada del último gran fichaje extranjero al equipo, el goleador inglés Jack Mortimer. Culé confeso y recalcitrante, como nunca dejaría de proclamar, Montalbán muestra en esta novela los entresijos del club de sus desvelos, aunque sin nombrarlo directamente en ninguna ocasión, a la vez que deja al descubierto la violencia tanto simulada como real que rodea al fútbol y que se "materializa en las gradas o fuera del campo" (Vázquez Montalbán 1988: 50). La trama se organiza en torno a los anónimos amenazantes que recibe la nueva estrella del Barça mientras, lejos de los focos, el viejo delantero apura sus últimos años en el Centellas, un equipo de regional. Alberto Palacín será asesinado en un crimen movido por los intereses urbanísticos del presidente del Barcelona, Basté de Linyola, en tanto se descubre que el autor de los anónimos era el relaciones públicas del equipo. A través de esta novela, Vázquez Montalbán describe el clima político y social de la Barcelona de finales de los ochenta, para lo que no duda en recurrir al fútbol y al retrato ficcional de algunos personajes de aquella época. Si en las figuras de Mortimer y Palacín es posible descubrir a los futbolistas reales Gary Lineker y Juan Manuel Asensi (Díaz Arenas 1997: 14-15), en el presidente asoman rasgos del que era por entonces el máximo dirigente del equipo, el constructor José Luis Núñez. La ficcionalización y la visión crítica de la sociedad catalana a través de la mirada de Carvalho emplea en esta novela el mundo del fútbol como un perfecto ejemplo, de los muchos llevados a cabo dentro de la obra de Montalbán, del "mestizaje de los discursos artísticos a través del collage y de la destrucción de las fronteras canónicas genéricas" (Izquierdo 2013: 16).

El libro de Manuel Vázquez Montalbán abrió la veda a la presencia del fútbol en las obras de género negro dentro de la literatura hispanoamericana. Con mayor o menor fortuna, escritores a ambos lados del Atlántico se valieron de la potencialidad del fútbol como puerta de entrada a la corrupción imperante en casi todas las esferas de la sociedad. A mediados de la década de los noventa, Julián García Candau pronosticaba que la incorporación del fútbol a la literatura de ficción podía encontrar en la novela negra una de sus mejores vías (1996: 329). Poco tiempo después, el boliviano Luis $\mathrm{H}$. Antezana escribía un pionero artículo sobre "Fútbol y novela negra", donde insistía en que "no es imposible que el lado comercial y financiero del fútbol, ése que se pierde en las lejanas "altas esferas» del dinero y del poder, permita explorar literariamente escenarios análogos" (Antezana 1998: 83). Por aquellos años, algunos autores que ya habían situado al fútbol entre sus obsesiones literarias, como los argentinos Osvaldo Soriano o Juan Sasturain, tomarían el testigo de Manuel Vázquez Montalbán, abriendo un espacio para el fútbol en el neopolicial latinoamericano, género donde se dan cita tanto la novela de procedimiento o el hard boiled, como las más variadas expresiones de la cultura popular, siempre con el objetivo de reflejar las "facetas más oscuras de la condición humana" (Noguerol 2006). Roberto Fontanarrosa,

bres con habilidades especiales en su mansión, de la que el protagonista tratará de huir con su enamorada, terminando por asesinar al millonario. La obra de teatro sería llevada al cine en una película del mismo título estrenada en 1961 y dirigida por René Mugica. 
considerado por muchos como el mayor exponente de la literatura del fútbol, jugaría con algunas de las convenciones del género negro en varios de sus relatos y novelas como Best Seller (1981) y El área 18 (1982), obra cuyo tono paródico y apocalíptico encontraría eco en El último campeonato mundial (1997), del mexicano Pedro Ángel Palou. Otros reconocidos autores de la narrativa policial latinoamericana que se acercaron al fútbol en algún momento de su producción, principalmente a través del relato breve, fueron el chileno Ramón Díaz Eterovic y el argentino Mempo Giardinelli.

En España, más allá del lado épico del balompié abordado desde los años veinte por poetas como Rafael Alberti o novelistas como Juan Antonio de Zunzunegui, encontramos un precedente del fútbol como motivo en la tradición del género policiaco dentro de la novela Los atracadores (1955), de Tomás Salvador, donde una banda de delincuentes formada por tres jóvenes de Barcelona es detenida durante un partido que enmarca el clímax de la narración. En los noventa, dejando de lado la narrativa juvenil, podemos destacar la presencia del fútbol como uno de los ejes del libro El hombre solo (1993), de Bernardo Atxaga, escrito originalmente en euskera. Novela de misterio ambientada en el Mundial 82, el fútbol resulta fundamental dentro de la descripción psicológica de un antiguo etarra que se hospeda en un hotel de Barcelona junto a la selección de Polonia: "Y aquel jugador que había marcado el gol era él mismo, y gracias a aquel gol su equipo subía de categoría, y él oía los aplausos, veía los jerséis de la gente en el aire, y detrás de aquellos jerséis una fábrica con una chimenea muy larga" (Atxaga 2008: 41). También, aunque en este trabajo no nos detendremos en la narrativa breve, apuntaremos la presencia de varios relatos de género negro en las dos antologías de cuentos de fútbol editadas por Jorge Valdano a finales de la década de los noventa (1995 y 1998) y que, además de suponer la incorporación de algunos autores canónicos a la literatura de tema futbolístico, alcanzaron también un gran éxito de ventas. Entre estos relatos donde el fútbol sirve de punto de partida para dejar al desnudo los cimientos de una sociedad corrupta encontramos "La poda del olivo", de Ángel Fernández-Santos; "El gol del triunfo", de Joaquín Leguina; o "El extremo fantasma", de Juan Villoro.

En la primera década del siglo xxı, esta tendencia se consolida, dando lugar a multitud de títulos que, en unos casos, simplemente pretenden aprovechar el tirón del fútbol para lograr mayores ventas mientras que, en otros, tratan de sacar partido a las posibilidades literarias del deporte como forma de retratar la violencia explícita o implícita ejercida por los poderes fácticos, empleando el fútbol para encarnar una "visión coherente y contradictoria del mundo contemporáneo" (Bromberger 1999: 33). La literatura española e hispanoamericana nos ha proporcionado a partir del año 2000 una amplia muestra de novelas de género negro donde el fútbol desempeña un papel determinante en tramas por las que desfilan presidentes corruptos, ultras sanguinarios, jugadores homicidas, entrenadores maquiavélicos, periodistas redentores y otros personajes de similar calaña. Trazaremos aquí una panorámica en torno a las relaciones entre el balompié y la narrativa policial en la literatura hispánica del siglo xxı para detenernos después en las dos novelas que serán el objeto principal de nuestro 
trabajo por su acierto a la hora de emplear el fútbol como motivo desde el que acercarse a los mecanismos de funcionamiento del poder en determinados periodos históricos: Todo está perdonado (2011), de Rafael Reig, y La pena máxima (2014), de Santiago Roncagliolo. La nómina de las novelas citadas en el siguiente recuento, más allá de su dispar categoría literaria, sirve para poner de relieve la existencia de una dinámica que lleva a numerosos escritores a fusionar el fútbol y la novela negra en una "moda" editorial que está alcanzando su mayor producción en los últimos años.

La década arranca en España con la novela El futbolista asesino (2000), del canario Nicolás Melini, que describe a un futbolista heredero del espíritu de Míster Hyde, idolatrado por los hinchas pero psicópata fuera del campo. Tres años después vería la luz El factor Rh (2003), novela satírica del leonés Carlos Eugenio López con presencia de algunos elementos del género negro en una trama coral donde un entrenador que representa a un portero africano a punto de fichar por el Athletic de Bilbao acaba siendo señalado por la violencia terrorista. El periodista Óscar Castellanos, con Aquel gol del 57 (2005), rememoró la figura de Di Stéfano dentro de una historia urdida en torno a un secuestro. Con un tema similar, aunque mucho más desarrollado, el madrileño Miguel Mena conseguiría el Premio Málaga de Novela con Días de tregua (2006), libro que ficcionaliza el secuestro del delantero del Barcelona Quini, ocurrido en 1981. Este mismo motivo aparecerá reformulado en la novela policiaca Hat trick (2008), del catalán Andreu Martín, donde no faltan los jugadores raptados ni los narcotraficantes colombianos. En 2007 se editaría El abrazo del alma, de Gonzalo Fleitas, sobre un periodista español que, después de ser enviado a cubrir el Mundial de Argentina de 1978, se ve inmerso en una investigación sobre los desaparecidos. Un año después, David Gistau sacaría a la luz Ruido de fondo (2008), thriller donde el asesinato de un hincha del Bayern Múnich por los Ultras Sur durante una imaginaria final de la Liga de Campeones deja al descubierto el pasado violento del personaje principal, periodista de éxito que se infiltra en la banda para resolver el crimen.

Miguel Mena continuaría profundizando, siete años después de Días de tregua, en las relaciones entre fútbol y novela negra, de nuevo en el contexto de la Transición española, en su libro Todas las miradas del mundo (2013). Desde la misma portada, donde aparece el "entrañable" Naranjito junto a unos agujeros de bala, se nos anuncia una trama ambientada en la España de 1982, centrada en la investigación del policía Luis Mainar en torno a la desaparición en Málaga de un miembro de la selección neozelandesa, mientras de fondo sobrevuela la amenaza del terrorismo. El año 2013 nos dejaría dos novelas negras de fútbol escritas por mujeres. Por un lado, la asturiana Laura Estévez publica Fuera de juego, donde narra la experiencia de una periodista deportiva que descubre una red de amaño de partidos contralada por las mafias internacionales. Por su parte, Paz Castelló, antigua jefa de prensa del Hércules FC, también emplea la voz de una periodista para describir la "cara oculta" del fútbol en La muerte del 9. Este mismo año, el catalán Daniel Vázquez Sallés, hijo de Manuel Vázquez Montalbán, publica El intruso (2013), libro de intriga ambientado en la Barcelona 
de 2020, donde se describe el acenso de Marcial Cárdenas, escritor que ficha por el Barça como traductor y que se acabará convirtiendo en el entrenador del equipo. Como ocurre en Mercado de invierno de Philip Kerr, en la novela de Vázquez Sallés nos topamos con otro trasunto del portugués José Mourinho. El mismo entrenador, en esta ocasión con su propio nombre, aparece en Las cuatro torres (2014), de Leandro Pérez, en la que un antiguo militar Ilamado Juan Torca recibe el encargo de descubrir quién es el "topo" que filtra las informaciones del vestuario del Madrid durante la etapa de Mourinho, al que se describe como un "tipo conspiranoico, grosero y retorcido" (Pérez 2014: 76). Este año asistiría también a la publicación de El fútbol no es así, novela escrita a cuatro manos por Pedro Torrens y Javier Tebas, actual presidente de la Liga de Fútbol Profesional.

Por lo que se refiere a las relaciones entre fútbol y género negro en la literatura latinoamericana, señalaremos algunos de los libros más destacados de los últimos años. El argentino Eduardo Sacheri, considerado por muchos como el mejor escritor de literatura futbolística en la actualidad, convirtió el amor incondicional a unos colores en un macguffin de la trama de La pregunta de sus ojos (2005), novela llevada al cine cuatro años después como El secreto de sus ojos, ganadora del Oscar y dirigida por Juan José Campanella. El argentino Sergio Olguín publicó en 2008 la novela Lanús, donde las lealtades creadas en la infancia en torno a un balón -“Qué sería de ellos si no tuvieran el fútbol. De qué hablarían, cómo se relacionarían, cómo podrían agredirse sin dañarse si no tuvieran el fútbol" (Olguín 2008: 201) - involucran al protagonista en la resolución del asesinato de un amigo a manos de una banda que domina el barrio. El colombiano Ricardo Silva Romero, con la novela Autogol (2009), ficcionalizó la muerte del defensa central Andrés Escobar, asesinado en su ciudad Medellín después de haberse marcado un gol en propia puerta durante el Mundial de Estados Unidos en 1994. El libro cuenta en primera persona la historia del imaginario comentarista Pepe Calderón Tovar que, después de perder la voz en el mismo momento en que Escobar se marca el gol, toma la decisión de asesinarlo para vengarse por la humillación sufrida: "Ninguno en ese infierno imaginaba que yo no volvería a hablar jamás ni mucho menos que me empeñaría en ser el asesino" (Silva Romero 2009: 13). El argentino Horacio Convertini escribió en 2008 El refuerzo, donde el Tanque Millán, un futbolista en plena decadencia, acaba huyendo para no terminar asesinado por el presidente de su nuevo equipo. La presencia del género policial en la obra de este autor se vería acentuada en El último milagro, ganadora del premio Extremo Negro BAN 2013 y publicada en 2014, donde aborda el poder de las barras bravas en Argentina dentro de una trama de "fútbol-ficción" en la que el presidente del Racing Club de Avellaneda, ante el riesgo de descenso, se embarca en un experimento tecnológico con el que pretende convertir al delantero centro del equipo en una especie de nuevo Messi o Maradona. 
Nos han metido hostias de todos los colores. ¡Vamos a demostrarlos ahí! ¡Vamos a demostrarlos ahí! Y cuando estoy cansado levanto la mano y sale un compañero.

Luis Aragonés, 10 de junio de 2008

Rafael Reig ${ }^{6}$ consiguió el vı Premio Tusquets de Novela con Todo está perdonado, un libro que, según el jurado, "sin dejar de lado el humor, recupera la historia reciente de España y la reinterpreta con un enfoque inédito en la literatura hispana". La novela retorna al escenario fantástico de un Madrid navegable, "ciudad líquida" ya dibujada por Reig en otros libros como Sangre a borbotones (2002) o Guapa de cara (2003), obras donde también conocíamos al "melancólico detective" Carlos Clot. El argumento de esta novela en la que el género negro, el humor y la política-ficción se ponen al servicio de una mirada crítica de la historia de España se centra, en primer término, en el asesinato por envenenamiento de Laura Gamazo, hija de Perico Gamazo, uno de los grandes empresarios del país. El padre encargará la investigación del crimen al agente de inteligencia retirado Antonio Menéndez Vigil, voz narrativa del texto, que contará en su pesquisa con la ayuda de Carlos Clot. Entre toques de un humorismo delirante que por momentos nos llevan a pensar en las novelas de misterio de Eduardo Mendoza, iremos descubriendo detalles en torno a la familia Gamazo, descrita por Rafael Reig como una saga heredera de un poder prácticamente absoluto mantenido a lo largo de los últimos ochenta años. A lo largo de la novela, para señalar algunos de los hechos más destacados, veremos cómo otro de los hijos de Perico Gamazo, llamado Nacho, acabará formando parte de la banda terrorista Grapo por la influencia de la criada de la casa, llamada Charo. Entre crímenes familiares y mujeres fatales no tan mujeres, desembocaremos en un desenlace crepuscular protagonizado por Charo y Carlos Clot. Todo ello en un Madrid fantástico pero al mismo tiempo hiperrealista que, tras agotarse el petróleo en los años setenta, se ha convertido en una metrópolis completamente inundada donde sus habitantes navegan por lugares como el gran Canal Castellana, la dársena Delicias o Puerto Atocha. Nos hallamos en una urbe decadente donde, tal y como señala el propio autor, "la sensación dominante es que todo está por debajo del agua que inunda la ciudad $y$, aunque no acaba mal, se trata de una esperanza muy desolada" (Maristain 2012).

En Todo está perdonado el fútbol se nos presenta como uno más de los mitos fundacionales que articulan el discurso oficial sobre la historia reciente de

\footnotetext{
${ }^{6}$ La obra de Rafael Reig (Cangas de Onís, 1963) se compone de los siguientes libros de ficción: Esa oscura gente (1990), Autobiografía de Marilyn Monroe (1992), La fórmula Omega (1998), Sangre a borbotones (Premio de la Crítica en Asturias, 2002), Guapa de cara (2003), Hazañas del capitán Carpeto (2005), Todo está perdonado (2011), Lo que no está escrito (2012) y Un árbol caído (2015). También ha publicado libros de artículos y crítica literaria como Manual de libros para caníbales (2006) y Visto para sentencia (2008).
} 
España. Tomando como punto de partida la victoria de la selección española en la Eurocopa de 2008, el libro adopta como marco cronológico el papel desempeñado por el equipo nacional en diversas competiciones europeas: 1964, 1984 y 2008. La misma estructura de la novela revelará la importancia que juega el fútbol como símbolo y síntoma del estado de la nación, quedando organizada en cuatro capítulos bajo el título de los partidos que ha de jugar el equipo: "Fase eliminatoria: Examen de conciencia", "Cuartos de final: El dolor de los pecados", "Semifinales: El propósito de enmienda" y "Final: La penitencia". El mismo título del libro, aunque enunciado por diversos personajes, encuentra su razón de ser en unas palabras del entrenador y oráculo de aquel equipo ganador en 2008, Luis Aragonés, palabras pronunciadas durante la celebración del triunfo: "«Todo está perdonado», declaró Luis Aragonés, el victorioso seleccionador nacional tras recibir la ovación unánime" (Reig 2011: 354). ${ }^{7}$ Esta frase le servirá al autor para condensar a la perfección el espíritu de la novela, resumido en la idea de una tabula rasa llevada a cabo de forma continua por los grandes poderes económicos y políticos del país. Tanto la trama policiaca como el marco cronológico se pondrán al servicio, casi en el sentido en que lo proponían Manuel Vázquez Montalbán y posteriormente Rafael Chirbes, de revisitar la memoria dominante con el propósito de desmitificar ciertos relatos hegemónicos como el de la transición, casi incuestionable hasta los últimos años en el ámbito político. A través de la familia Gamazo y de la selección española de fútbol, Reig pone de manifiesto los déficits de la democracia y "subraya aquella continuidad de la élite, la impunidad en la que vivieron y el perdón que gozaron por las leyes de amnistía como intento de reflexionar sobre los supuestos defectos del tránsito" (Colomer 2012: 258).

Como decíamos, la novela sitúa su escenario principal en el verano de 2008, con la población siguiendo masivamente los partidos de la selección en la Eurocopa de Suiza y Austria. A través de la voz patriótica y entregada a la causa de Menéndez Vigil, desde el primero de los partidos se nos transmite la idea de un discurso acerca de la construcción nacional donde el fútbol desempeña un papel preponderante. España ha cambiado en el terreno de juego, su estilo es diferente, rápido, espectacular, desde la llegada de Luis Aragonés el equipo ha dejado atrás el apodo de "La furia" para pasar a ser conocido como "La Roja": "Desde por la mañana, en la calle se oía decir que había otra España. que podíamos, oé, oé, oé, y ese día del partido decisivo contra Suecia se multiplicaron las comuniones" (17). Es decir, la selección se ha transformado a la par que el discurso del narrador, capaz de transitar de los dogmas de la dictadura a los de la democracia sin mayores problemas. El fútbol, de este modo, ayuda a poner de relieve la maleabilidad ideológica de las élites, mostrando a las claras su refinada capacidad de adaptación. El escritor aporta verosimilitud a este proceso relatando aquellos partidos de junio de 2008 como una crónica que mantiene el nombre de los jugadores y la narración de los goles tal y como ocurrieron, incorporándolos a esa Madrid líquida donde la gente se desplaza en barco o en

\footnotetext{
${ }^{7}$ A partir de aquí citaremos este libro solo con los números de página.
} 
canoa. Sostiene Vicente Verdú al respecto de la crónica de fútbol que "el relato de un partido como tantos cuentos populares no tiene el aliciente del final [...]. El interés por la crónica radica en el conocimiento del proceso por el cual se ha cumplido ese desenlace" (Verdú, 1980: 176). La novela de Rafael Reig actúa en el mismo sentido, es decir, lo que nos interesa, dado que el resultado final ya lo conocemos, es el proceso, la construcción de la identidad. O, dicho de otra forma, no importa tanto la trama en torno a la cual se suceden los acontecimientos sino lo que esta trama nos acaba revelando, no importa tanto que Madrid sea una nueva Venecia sino lo que se oculta en el fondo de su lecho cenagoso.

El fútbol, gracias a ese equipo de "jugones" y "locos bajitos" encarnado en Iniesta o Xavi Hernández, nos ofrece la estampa de otra España posible pero, eso sí, alejada de cualquier modificación sustancial en lo que se refiere a su realidad social y económica: "Otra España era posible. Cómo no. Indolora y sonriente, sin una voz más alta que otra, la continuación incruenta de nuestra Historia, después de un paréntesis de anuncios sometidos a todo volumen" (61). Las revoluciones, parece decirnos el autor, solo resultan tolerables para el poder si se producen dentro de aquellas manifestaciones colectivas desprovistas de toda carga crítica, como puede ser el caso del fútbol. El papel de la selección española en diferentes eurocopas le servirá a Reig como un escaparate idóneo para organizar el retrato de una arquetípica familia burguesa como los Gamazo y, al mismo tiempo, como símbolo de la evolución del país. De esta forma, la España que se alzó con la Eurocopa de 1964, gracias al gol de Marcelino contra la Unión Soviética en el Santiago Bernabéu, será una España heroica, carpetovetónica, épica al modo virgiliano: "No soy quién para evocar aquí de nuevo la heroicidad de nuestra selección o para cantar las armas y al hombre, Marcelino, que dio el triunfo a España, (arma virunque cano)" (210). Será la España del "fútbol racial, el de la furia española, también la precisión del fútbol de seda" (143), el país franquista de las primeras cinco Copas de Europa donde el Real Madrid era el mejor embajador posible, aquella nación que sigue contemplando con irrenunciable nostalgia Menéndez, el agente que ahora se mueve como pez en el agua por las "cloacas del Estado de Derecho" después de haber servido durante décadas a la dictadura: "Allí estaba yo, con otros 119.999 españoles, y todos tuvimos una conducta ejemplar. Era la segunda Eurocopa, más conocida entonces como Copa Europea de Naciones. La primera la había ganado la URSS. Allí estaba y, con mis prismáticos (los mismos Zeiss que aún conservo), distinguí en el palco al Caudillo y a doña Carmen Polo (210).

Tras un salto de casi veinte años, el equipo volverá a tener una buena actuación a principios de los ochenta. La épica de un partido como el "glorioso" 12-1 que le endosó la selección a Malta el 21 de diciembre de 1983, dentro de la fase de clasificación para el torneo de 1984, le sirve al escritor asturiano para poner el dedo en la llaga sobre la continuidad del franquismo "por otros medios". Reig salpica la crónica de aquella goleada histórica con algunos tópicos de un país apenas evolucionado respecto al que ganó a la URSS: "Los fueras de juego de Rincón también se negaba a verlos, como si fueran la sangre de Ignacio Sánchez Mejías sobre la arena: Que no. Que no quiero verla. [...] ¿Esa falta en el área? 
No. Que no. No me la señaléis. Que no quiero verla" (227-228). Además de que la referencia al poema de Lorca sea del todo pertinente -Ignacio Sánchez Mejías fue presidente del Real Betis Balompié, en cuyo estadio se disputó el partido contra Malta-, el narrador pone de relieve la importancia del árbitro en aquella noche que, dentro del discurso épico del fútbol, todavía resulta difícil poner en tela de juicio. Rafael Reig viene a decirnos que, como en la política, nada de aquello fue glorioso, que en verdad todo ocurrió como tenía que ocurrir, con unas buenas dosis de violencia y con más intimidación que consenso, con las necesarias presiones ejercidas por el público: "A Bonello le llovían los balones por delante y proyectiles por detrás: naranjas, pan y alguna botella de cerveza. De acuerdo, quizá no dimos una muestra de civismo, pero ese momento lo que hacían falta eran testículos" (228). Como si se llegaran a equiparar el relato de la Transición española y el del 12-1 a Malta, Reig desmitifica a través de la ironía y de la hipérbole aquellas construcciones de sentido que dejan de lado toda posibilidad de sospecha. La novela se puede enmarcar entonces, junto a otras obras del mismo periodo, en la voluntad de determinados autores españoles de denunciar los procesos mediante los cuales los protagonistas del franquismo lograron perpetuarse en la democracia:

La impugnación del mito de la transición ha traído de la mano, en no pocos autores, la manifestación de una desconfianza creciente con respecto al paradigma cultural surgido de esta forma de tránsito de la dictadura postfranquista a la democracia, y ha subrayado los elementos de continuidad del modelo autoritario en el modelo democrático. (Ros 2013: 153)

Se trata de una desconfianza que permea toda la obra de Rafael Reig y que se manifiesta en otras novelas coetáneas que, además, de revelar una conciencia crítica respecto al discurso hegemónico, señalan a su vez la existencia de una deriva ideológica recogida por el mundo editorial. Entre estas novelas que cuestionan el mito de la transición, por nombrar algunas de las que se publicaron casi en paralelo a la de Reig, se encontrarían Hilos de sangre (2010), de Gonzalo Torné; Operación Gladio (2011), de Benjamín Prado; Un momento de descanso (2011), de Antonio Orejudo; y El jardín colgante (2012), de Javier Calvo. Dentro de este grupo también podríamos añadir las dos novelas de Miguel Mena que hemos mencionado anteriormente, en las que a través de la voz del joven policía Luis Mainar descubrimos cómo la violencia de los llamados "años de plomo" afectó a todos los estamentos de la sociedad. En Días de tregua, sin ir más lejos, la ficcionalización del secuestro real del máximo goleador de la Liga, Enrique Castro "Quini", nos muestra el clima prebélico que imperaba en el país por aquel entonces y del que nada, incluido el fútbol, podía quedar al margen:

Si alguien quiere extender la sensación de inseguridad, nada mejor que atacar también al deporte más popular. Que nada se quede fuera de la ola de inestabilidad: el ejército, la policía, el gobierno, el parlamento, la corona... y ahora el fútbol, la liga, quizá lo único que vertebra de verdad a este país, donde incluso los que más se odian saben que necesitan del equipo rival para existir. (Mena 2006: 20-21) 
Hablamos de libros que tratan de cuestionar el discurso canónico para presentar relatos alternativos que, en algunos casos, recurren a la parodia como forma de denuncia social. En nuestro caso, el fútbol es un elemento más dentro del pacto de silencio que siguió a la muerte del dictador, un canalizador de voluntades que seduce con su espectáculo y que, para alguno de estos escritores, sirve en ocasiones como eficaz mecanismo de control por parte del poder hegemónico. Las herramientas de la novela negra -la voz desencantada de sus personajes, los asesinos presentados como víctimas- ayudarán a sustentar esta revisión de los mitos fundacionales del relato de la historia de España con los que Rafael Reig busca fomentar el debate en el lector sin renunciar a la capacidad de entretenimiento asociada al género. El mismo escritor ha manifestado su admiración por algunos de los maestros de la novela negra como Chandler, Hammett o James Cain. En Todo está perdonado, la trama policiaca en torno a los crímenes y suicidios en la familia Gamazo, urdida en relación al tiempo marcado por los partidos de la selección española, generará una alianza entre fútbol y novela negra puesta al servicio de una distopía hiperrealista en la que, si bien Madrid se ha convertido en una "ciudad líquida", todo permanece en esencia igual que antes, revelando a lo largo de la narración la eficacia del adagio popularizado en El Gatopardo: "Si queremos que todo siga como está, es necesario que todo cambie". La construcción hiperbólica de la sátira se llevará a cabo mediante fórmulas que desnudan la amnesia colectiva, plasmada en la idea cristiana del perdón, presente desde el mismo título y traducida, por ejemplo, en el empleo reiterado de expresiones como la "Inmaculada Transición" o la "redención de España" merced al fútbol.

En este sentido, cabe destacar el retrato disparatado de la religión que nos presenta el autor asturiano. Perico Gamazo, sin ir más lejos, hará fortuna como empaquetador de hostias consagradas después de un delirante accidente donde llega a intervenir el mismísimo Papa. La sociedad asistirá incluso a las disputas entre sectas antediluvianas como los neognósticos o los bucalistas, presentadas como auténticas bandas urbanas y criminales. La religión lo impregna todo en una sociedad que ha llevado al límite las posibilidades ecuménicas del nacionalcatolicismo. El fútbol también se verá imbuido de la sacralización de lo cotidiano que se da en el libro de Reig, presentándose como una fe que, lejos de considerarse herética, se ve consagrada por el poder y por el fervor de los hinchas. Así, en la descripción de un gol decisivo de Antonio Maceda en la Eurocopa de Francia de 1984, se hará un juego de palabras entre las identidades del asistente, Juan Señor, y de Cristo: "Maceda, el héroe, lo explicó a divinis, como un humilde pastor retransmitiendo una aparición mariana: «El envío de Señor me llegó diáfano»" (240). La potencialidad redentora asociada al fútbol alcanzará su momento álgido en la Eurocopa del 2008: "Tras la batalla se celebró un Te Deum con el recuerdo a los caídos, como Villa, el héroe trágico al que el fantasma del 7 le había puesto la zancadilla. Iker Casillas consagró el balón" (301). Después de la victoria en la final, tras la absolución colectiva culminada en el éxtasis del 1-0 contra Alemania, se dará inicio al proceso de beatificación y elevación a los altares de los principales protagonistas de la gesta: "Fue el centésimo octogésimo día del calendario gregoriano, festividad de San Pedro y San Pablo, aunque 
enseguida se elevó una propuesta al Ministerio para consagrarlo a San Luis Aragonés y San Fernando Torres" (355).

En definitiva, como pretende denunciar el escritor, los valores de España se mantienen casi inalterables con el paso de los años, tal es el caso de la religión que, lejos de perder capacidad de influencia, continúa siendo una fuerza determinante, axiomática. Más allá del discurso oficial sostenido en los mitos historiográficos, para Reig permanece instalada la división entre vencedores y vencidos; en verdad no se ha producido ninguna reconciliación, todo ha sido perdonado, olvidado, para que así puedan seguir mandando los mismos que han mandado siempre. La "Inmaculada Transición", por encima de amnistías y leyes de punto final, quedaría entonces como "aquella oportunidad perdida para un país históricamente sustentado en el fracaso" (Colomer 2012: 258). El fútbol, a pesar del maravilloso estilo implantado por Luis Aragonés, solo tiene la potestad de cambiar la disposición de unos jugadores sobre el césped, jamás la verdadera historia del país, en contra de lo que se empeña en proclamar Menéndez, haciéndose eco de la retórica que envolvió la victoria de España en aquella Eurocopa: "Había un equipo nuevo, "el equipo del cambio», un conjunto sin vedettes ni caudillos, espejo de la profundidad y de la calidad de nuestra democracia, de nuestra cohesión social" (298).

El personaje de Antonio Menéndez Vigil, su voz narrativa, encarna en esta novela la capacidad de adaptación de los poderosos a lo largo de la historia, la verborrea camaleónica de su discurso. Los mismos que en la novela insisten en definir a la selección de 2008 como un "equipo del cambio" son aquellos que nunca cesarán de oponerse a los cambios en la sociedad española, aquellos que han sabido adaptar su discurso al momento histórico que les ha tocado vivir: "La tortilla puede dar la vuelta, pero arriba siempre están los mismos", tal y como manifestó el propio autor en una entrevista (Maristain 2012). O, como diría un entrenador de fútbol, cuando se lesiona un jugador sencillamente entra al campo otro compañero. Todo lo dicho hasta aquí, la fusión entre el fútbol y el género negro, la mirada crítica de la sociedad española, alcanzará su apogeo en una de las escenas finales del libro, donde la sátira y el esperpento se ven llevados al extremo. El escritor, a través de la atónita mirada del agente Menéndez Vigil, narra el grotesco naufragio de la gabarra donde los jugadores de la selección española, acompañados por "las más altas instituciones del Estado", se dirigen a ofrecer la Eurocopa a la diosa Cibeles. La única reconciliación nacional que ha existido, deja caer Rafael Reig en plena apoteosis futbolística, es aquella que nos confunde a todos, héroes o villanos, en el "légamo tenebroso de la Historia":

El equipo se alineó sobre la cubierta de la gabarra. Delante de ellos se colocó la representación de las más altas instituciones del Estado: S.M. el Rey, el presidente del Gobierno, el de la Conferencia Episcopal y los de las principales empresas del Ibex, todos rígidos, solemnes, hieráticos y de perfil, como esculturas egipcias.

La gabarra emprendió una majestuosa y lenta navegación hacia Isla Cibeles para hacer entrega de la copa a la Madre de los Dioses.

Era el momento más grave y decisivo de la Historia de España: la hora de la redención. 
Entonces se oyó el estallido.

La estatua de la diosa saltó en pedazos y la isla entera desapareció en el agua negra del canal.

La gabarra volcó y, aunque todos los ocupantes consiguieron ganar la orilla a nado, la copa se hundió sin remedio y quedó sepultada en el légamo tenebroso de la Historia. (357)

\section{La PENA MÁxima (SANTIAgo RonCAgLIOLO, 2014)}

Pido a Dios Nuestro Señor que este evento sea realmente una constitución para afirmar la paz, esta paz que todos deseamos, para todo el mundo y para todos los hombres del mundo.

Jorge Rafael Videla, 1 de junio de 1978

En La pena máxima, el escritor peruano Santiago Roncagliolo 8 recupera la figura del detective ocasional Félix Saldívar Chacaltana, quien ya fuera protagonista de su novela Abril rojo (2006), ganadora del Premio Alfaguara. En aquel libro, la investigación de una serie de crímenes ocurridos durante la Semana Santa del año 2000 en la provincia de Huamanga durante el gobierno de Alberto Fujimori le servía al autor para mostrar el clima de violencia imperante en las zonas rurales a través de una novela negra articulada como "excusa discursiva para que las víctimas del olvido hablen de su desgracia" (Salinas 2007: 10). Descubríamos entonces a Chacaltana, por entonces fiscal del distrito, un ciudadano ejemplar, amante del orden, que se veía abocado a descubrir de primera mano una realidad oculta que no encajaba en sus rígidos esquemas mentales definidos por los límites procesales del código civil. Con La pena máxima, Roncagliolo nos lleva veinte años antes, presentándonos a un Chacaltana más bisoño si cabe, asistente de archivo en Lima, devotamente entregado a la causa, funcionario metódico y eficiente que se verá envuelto en una trama criminal desarrollada en paralelo a los partidos de la selección peruana en el Mundial de 1978, celebrado en Argentina. Con esta precuela, ${ }^{9}$ tal y como ocurría en Abril rojo, Roncagliolo empleará los instrumentos de la novela negra, aliados aquí con la crónica futbolística, para reflejar la represión latente en una sociedad que, como Chacaltana, cree vivir en paz y bajo el amparo de la ley pero donde, en realidad, "la violencia

\footnotetext{
${ }^{8}$ Santiago Roncagliolo (Lima, 1975) ha publicado las siguientes novelas: El príncipe de los caimanes (2002), Pudor (2004), Abril rojo (2006), Memorias de una dama (2009), Tan cerca de la vida (2010), Óscar y las mujeres (2013) y La pena máxima (2014). También ha escrito libros de cuentos como Crecer es un oficio triste (2003) y de no ficción: El arte nazi (2004), La cuarta espada (2007), Jet Lag (2007) y El amante uruguayo (2012).

9 Emplearemos el término de "precuela", al ser el que más fortuna ha obtenido gracias sobre todo al mundo del cine y la televisión, por encima de otras denominaciones más técnicas para referirse a una historia cuya continuación se realiza "hacia atrás", como es el caso del concepto de "simulación analíptica", planteado por Genette y recogido por Pedro Javier Pardo (2010: 46).
} 
sustituye de cuajo la palabra y condena a los sujetos a la enajenación o la muerte al enfrentarse al conocimiento de su identidad" (Perilli 2010: 83).

La pena máxima se organiza en torno a seis capítulos que hacen referencia a los partidos de la selección peruana en el Mundial (disputados contra Escocia, Holanda, Irán, Brasil, Polonia y Argentina), además de un último capítulo dedicado a la final del campeonato (Argentina-Holanda). En un arco cronológico que abarca veinticinco días del mes de junio de $1978,{ }^{10}$ Félix Chacaltana Saldívar pasará de trabajar como un burócrata gris y abnegado a involucrarse en la investigación de la desaparición de su mejor amigo, Joaquín Calvo, búsqueda que le llevará a hundirse de pleno en los entresijos de la Operación Cóndor, la alianza criminal que, bajo el auspicio de los Estados Unidos, presidió las dictaduras americanas desde mediados de la década de los setenta. En la figura de Chacaltana, en ese numerario incapaz de entender que la ley puede llegar a no ser justa, descubrimos una vuelta de tuerca respecto al héroe arquetípico de la novela negra que lucha por una ley en la cual no confía y que sabe que no ha de lograr "ninguna reconciliación positiva con el sistema de valores vigente" (Savater 1983: 133). Remitiéndonos a dos arquetipos del género, podríamos decir que Chacaltana se encuentra mucho más cerca del candor del Padre Brown que del desencanto de Marlowe. Incluso el fútbol será para él algo completamente ajeno a su realidad, limitada apenas a los legajos del archivo en el que pasa sus días con feliz entrega funcionarial: "El fútbol quedaba fuera del universo mental de Félix Chacaltana, o si ocupaba un lugar estaba cerca de los ornitorrincos y los marsupiales, muy lejos de todo lo que le importaba" (Roncagliolo 2014: 22). ${ }^{11} \mathrm{El}$ protagonista será entonces, a medida que profundice en su búsqueda, cuanto más se sumerja en el horror de los desaparecidos, un héroe en contra de su voluntad, movido por acontecimientos a los que en primera instancia, como buen ciudadano, se resiste a dar crédito. El cuestionamiento de sus ideales y la sospecha acerca de todo aquello en lo que ha creído moldeará su estampa de "héroe frágil, desacreditado, al que ningún coro celebra", un personaje que "contrasta vivamente con la imagen clásica de la invulnerabilidad heroica, pero a la vez la completa" (Savater 1983: 134).

La novela de Roncagliolo se construye desde su mismo inicio como un montaje en paralelo entre las crónicas facticias de los partidos de la selección peruana en el Mundial y los avances de la investigación del asistente de archivo.

\footnotetext{
${ }^{10}$ La pena máxima no es la única obra literaria que utiliza como marco el Mundial de 1978. Además del libro de Gonzalo Fleitas que ya hemos mencionado (El abrazo del alma, 2007), el argentino Antonio Dal Masetto lo emplearía de trasfondo en su novela Hay unos tipos abajo (1998). E colombiano Luis Alejandro Díaz menciona en su tesis doctoral (Literatura y fútbol: otros horizontes de la literatura en España e Hispanoamérica) el cuento del mexicano Carlos Prigollini, titulado "Sentimientos encontrados" e incluido en la antología Cuentos mundialistas (2010). También podríamos añadir el poema "Mundial", de Carlos Ferreira, que concluye con los siguientes versos: "Lo malo fue el final, indigno y torpe: / aquellos cadáveres volviendo / al lecho de los ríos, / a las comunes fosas / meneando las cabezas, / canturreando una canción de olvido. / Y nosotros allí, con esos bombos, / con esas insensatas banderas sudorosas, / con el mundo al revés, / hechos pelota" (Ferreira 2010: 97). Más adelante nos detendremos en la novela Dos veces junio (2002), del argentino Martín Kohan.

${ }^{11}$ A partir de aquí citaremos los fragmentos de este libro solo con el número de página.
} 
La narración radiofónica de los encuentros marca el tono y la evolución de la pesquisa en un crescendo que culmina con la disputa de la final. Decía al respecto el escritor peruano en una entrevista que el papel del narrador de fútbol es el de un maestro de la palabra que "tiene que narrar algo que no estás viendo", hecho que le pareció interesante rescatar "literariamente" (Revuelta 2014: 4). En este sentido, siguiendo a Verdú, tal y como señalábamos en relación a la novela de Rafael Reig, observamos cómo, empleado literariamente en ambos casos, el "fútbol no ahuyenta la realidad, sino que la trae repetida y amontonada" (Verdú 1980: 185). Así como el narrador de un partido está obligado a reinventar la realidad de cara a hacerla perceptible para aquellos que no pueden contemplarla, el escritor de ficción trata de beneficiarse de los elementos de la crónica de fútbol para aportar mayor verosimilitud e intensidad a la narración de unos hechos determinados. El fútbol irrumpirá ya desde la primera escena del libro, donde presenciamos el asesinato de un personaje en el que más tarde descubriremos la figura del profesor de sociología Joaquín Calvo, amigo de Félix Chacaltana. El partido entre Perú y Escocia, saldado con una clara victoria de la selección latinoamericana, genera un ambiente de euforia incontrolable en toda la ciudad de Lima, provocando que sea imposible escuchar el disparo del asesino y el llanto de un bebé en medio de los "gritos triunfales" de la población tras el magnífico gol de falta de Teófilo Cubillas:

En ese momento el fragor de la victoria eclipsó todos los sonidos de Barrios Altos. Durante el grito triunfal que siguió, durante los abrazos y los besos y las carcajadas, nadie escuchó los llantos, amargos y desesperados, de un bebé en una mochila roja, y mucho menos el disparo final de un arma de fuego (16)

El fútbol sobrevolará a partir de entonces todo el libro como una salmodia que se cuela en las conversaciones de los personajes y que, según el resultado, determina el estado de ánimo de la mayoría de ellos. Un caso paradigmático será el del director del archivo donde trabaja Chacaltana, auténtico forofo que, por más que se empeñe, no logra involucrar en el clima emocional que se genera al amparo de los partidos a su asistente, preocupado siempre de mantener la normativa interna que proclama que los "eventos de índole cultural-deportivafolclórica no deberían intervenir con el sano y pacífico ejercicio de nuestras funciones" (58). Desde su inicial indiferencia casi bartlebiana, la confortable visión de la sociedad del asistente de archivo irá evolucionando a medida que la mejor selección peruana de la historia consiga nuevos logros en el torneo. Su realidad empezará a tambalearse en tanto vaya descubriendo las verdaderas actividades de su amigo Joaquín y el funcionamiento real de la maquinaria del Estado peruano, presidido en aquel entonces por el gobierno militar del general Francisco Morales Bermúdez. A pesar de resistirse como burócrata ejemplar, el cándido Chacaltana comenzará a formular preguntas incómodas a las que su jefe, entre otros, se apresura a dar respuesta: "En este país no pasan esas cosas, Felixito. No somos unos bárbaros [...] ¿Para qué enfadar a los que serán nuestros jefes dentro de poco? Además, si los presos se pusieran a gritar, no nos dejarían escuchar los partidos de fútbol" (156). 
La cháchara del fútbol lo presidirá todo durante aquel mes de junio de 1978 que vemos retratado en La pena máxima, su rumor no deja oír la detonación de un arma de fuego ni permite escuchar los gritos de los represaliados. La futbolización de la sociedad que se produce durante un Mundial se manifiesta perfectamente en algunas de las pinceladas con las que Santiago Roncagliolo nos describe la Lima de aquella época, una ciudad que apenas recupera su actividad "normal" cuando el equipo no está en la cancha: "Ese sábado no jugaba Perú, así que la vida salía a la calle. En la animación de las veredas, en las tiendas abiertas, en las radios a todo volumen de los bares y restaurantes se advertía el movimiento de un día normal" (77). Mientras Chacaltana, de la mano del almirante Carmona, empieza a entender que las "actividades subversivas" de su amigo eran en realidad producto de su condición de espía, el funcionario se irá introduciendo de manera paulatina en las "cloacas del Estado" hasta acabar formando parte, sin que él mismo llegue a darse cuenta en un principio, de la Operación Cóndor. El servilismo y sumisión de Félix Chacaltana simbolizarán el estado de ánimo de un país que, por aquel entonces, se encomendaba en su mayoría a la estabilidad defendida por los militares peruanos frente a otras dictaduras de mayor dureza como la chilena o la argentina. Esto quedará perfectamente plasmado en el grito que pronuncia un hincha al que una manifestación política no le deja regresar a casa a tiempo de ver el próximo partido: "¡Yo no quiero democracia, carajo! -gritó desde un Volkswagen escarabajo-. ¡Yo quiero ver el Mundial!" (181).

Llegamos entonces al capítulo organizado en torno a uno de los partidos más negros de la historia del fútbol, el Argentina-Perú disputado el 21 de junio de 1978 en el estadio Lisandro de la Torre, de Rosario. Antes de detenernos en el enfoque de Roncagliolo, es preciso recordar que el Mundial de Argentina fue uno de los ejemplos más sangrantes de uso político del deporte, situado a la par que los Juegos Olímpicos de 1936 en Berlín o el Mundial de 1934 en Italia. La Junta Militar aprovechó aquel evento como una gran operación de lavado de imagen con la que silenciar el asesinato masivo de los opositores. Mientras Videla proclamaba la paz "para todos los hombres del mundo" en su discurso de inauguración, a pocos metros se continuaba torturando a prisioneros que después serían arrojados vivos al mar. La selección argentina estaba obligada a ganar en lo que se consideró una misión de guerra, tanto que incluso se prohibieron las críticas al entrenador de aquel equipo, César Luis Menotti, ${ }^{12}$ al que se pasó a considerar un "funcionario" del Proceso de Reorganización Nacional. ${ }^{13}$

\footnotetext{
12 El papel esquizofrénico de Menotti, técnico de ideología socialista, sigue generando controversia a día de hoy. Mientras muchos, entre ellos el Nobel Adolfo Pérez Esquivel, continúan reprochándole su silencio; otros, como Jorge Valdano, aseguran que el entrenador arengó a sus jugadores en la final con las siguientes palabras: "Nosotros somos el pueblo, pertenecemos a las clases perjudicadas, nosotros somos las víctimas y nosotros representamos lo único legítimo en este país: el fútbol. Nosotros no jugamos para las tribunas oficiales llenas de militares sino que jugamos para la gente. Nosotros no defendemos la dictadura sino la Libertad" (Padilla 2013).

${ }^{13}$ Nombre dado por los propios militares a los gobiernos dictatoriales que se sucedieron en Argentina desde 1976 a 1983, dejando a su paso, según las organizaciones de derechos humanos, más de 30.000 muertos y desaparecidos.
} 
Volviendo al 21 de junio, la continuidad de Argentina en el torneo pasaba por ganar a Perú por más de cuatro goles. Con la selección peruana ya eliminada después de sus derrotas frente a Brasil y Polonia, los militares argentinos no escatimaron a la hora de asegurarse la victoria. Tal y como detalla Maximiliano Jara en su libro Historia del secuestro de una pasión, tras el partido, además de diversas transferencias de militares argentinos a sus colegas peruanos, se enviaron 35.000 toneladas de grano desde Buenos Aires y se descongeló una línea de crédito de 50 millones de dólares al gobierno de Perú (2012: 138). Además de llamadas previas entre los dictadores de ambos países, una "visita de cortesía" al vestuario antes del partido sirvió para que los jugadores comprendieran el respeto debido a la "hermandad latinoamericana" (Jara 2012: 139). Todo ello, como no podía ser de otra forma, propició un resultado de 6-0 a favor de Argentina. Roncagliolo recordaba en una entrevista la eficacia simbólica que aquel partido sigue teniendo a día de hoy:

Los militares peruanos no son unos criminales como los argentinos y los chilenos, pero cuando tu vecino es un asesino y tú no haces nada, terminas por convertirte en cómplice, y eso pasó en Perú. Resulta simbólicamente muy interesante el partido entre Argentina y Perú. Para Perú es inolvidable porque Argentina necesitaba ganar 4-0 para pasar a la final y nos dieron 6-0. Pasaron cosas raras: antes del partido, Videla y Kissinger bajaron a saludar a los peruanos. Y a mí, si me saluda Videla, me da mucho miedo. (Revuelta 2014: 5)

El narrador sitúa en el marco de este encuentro histórico, no precisamente por su espectacularidad sobre el terreno de juego, el capítulo más estremecedor de su libro. Félix Chacaltana ha aterrizado en Buenos Aires para proseguir su investigación como miembro del Plan Cóndor, cada vez más cerca de descubrir las razones ocultas tras el asesinato de su amigo. Una vez allí, será recibido por los militares argentinos, quienes lo llevarán a su destino entre bromas sobre el partido. Tras pasar por el "templo más grande del mundo" (314), el Monumental de River Plate, el asistente de archivo será conducido hasta la Escuela Mecánica de la Armada (ESMA), el mayor centro de tortura de la dictadura, situado apenas a diez esquinas del estadio y donde el fútbol se sigue con gran interés: "El gol fue recibido con una ovación. Ahora estaban en un piso de dormitorios, como el ala de un hotel. Aunque la mayoría de los militares se habían reunido a ver el partido en el salón de actos, quedaban suficientes en sus cuartos" (319). La incesante caída de los goles en la portería peruana, defendida por un portero nacido precisamente en Rosario, irá pautando el descenso de Chacaltana a través de los diferentes círculos de ese "Auschwitz argentino" (Galeano 1995: 175). La machacona letanía de la narración del partido por parte de los locutores lo sumergirá finalmente en el escenario dantesco de la maternidad, donde las torturadas conciben y alumbran a los hijos que habrán de serles robados por los militares justo antes de ser asesinadas:

Kempes busca a Ortiz. Lo encuentra. Ortiz corre hacia la línea de meta y saca un centro corto. Houseman recibe y... ¡GoooooollIIIIII! ¡Argentina 5-Perú 0! Houseman confirma la calidad del mejor wing derecho de la Argentina... 
Las dos chicas sonrieron. Una de ellas se acarició la barriga. Había algo irreal en su tranquilidad. Como si estuvieran en medio del infierno sin saberlo. (323)

Esta escena de la novela de Roncagliolo, la aparición del fútbol en el epicentro de la maquinaria represora de la Junta Militar, encuentra un antecedente en Dos veces junio (2002), del argentino Martín Kohan. En este libro también se lleva a cabo un montaje en paralelo entre algunos episodios del Mundial de fútbol con las torturas practicadas en los centros de detención. Kohan nos describe hasta el mínimo detalle la ficticia ejecución de una embarazada mientras, al mismo tiempo, se recita la alineación de la albiceleste en la final, incluyendo progresivamente sus nombres, sus posiciones, la procedencia, el dorsal, las fechas de nacimiento, la estatura y el peso. Si en Roncagliolo el protagonista es un funcionario que cree a pies juntillas en el funcionamiento del Estado, Kohan entrega la voz narrativa a un joven militar que también va descubriendo poco a poco su rol dentro del engranaje de la dictadura. Como si las dos novelas se hicieran eco la una de la otra, en el escritor argentino aparecerá también la idea de que durante los partidos resultaba imposible escuchar los gritos de los torturados, además de reflejar la imagen de la calma momentánea que la victoria proporciona a los verdugos: "En el silencio de la noche, había que esperar que explotara un grito de gol. Un gol de la Argentina, como había pasado las otras noches, y quizá no habría ya más gritos, al menos hasta el día siguiente" (Kohan 2011: 42). En el relato de los desaparecidos que pudieron sobrevivir a aquellos días en la Escuela Mecánica de la Armada, muchos recuerdan que los militares, en un refinamiento extremo de su tortura, los sacaron a pasear después de la victoria de Argentina debido a que en aquel momento de euforia colectiva nadie iba a prestar atención a sus Ilamadas de auxilio: "En un gesto de «hermandad», después de golpearlos los sacaron a la calle para que pudieran presenciar las celebraciones de la gente" (Jara 2012: 143). Como si a través de la literatura pudiera enmendar aunque fuera artísticamente aquel episodio, Martín Kohan hará que en su novela Argentina pierda la final del campeonato, ${ }^{14}$ para continuar detallando más adelante las torturas en otros episodios sobrecogedores. Si bien resultan evidentes las diferencias formales entre los dos libros, tanto el peruano como el argentino recuperan el relato de aquellos partidos de fútbol de junio de 1978 como estrategia narrativa que les permite acercarse al tema de los hijos robados,

\footnotetext{
14- Los componentes de aquella selección argentina, héroes en su momento, han cargado después con la acusación de haber servido a la dictadura de Videla, en oposición a los héroes de Mundial 86, vencedores ya en democracia. El escritor Eduardo Sacheri retrató perfectamente el sentimiento de culpa de aquella magnífica generación de fútbolistas en el relato "Los malditos", uno de cuyos párrafos dice así: "Campeones que cargan con la maldición de haber ganado el mundial equivocado. Culpables de un montaje propagandístico del que fueron meros instrumentos. Reos del delito de beneficiar a un régimen político ilegítimo del que ellos, sin embargo, no eran responsables. Ya imagino algún dedito acusador, alzado en contra de esta columna: «Si no querían ser cómplices, deberían haber renunciado». Ajá. Y mientras escucho la acusación, no puedo evitar preguntarme cuántos deberían haber renunciado, a cuántos empleos, para evitar esa complicidad. ¿Los jugadores sí, y los maestros de escuela no? ¿Los jugadores sí, y los bancarios no? ¿Los jugadores sí, y los empleados municipales no?" (Sacheri 2014).
} 
definido por Roncagliolo como "la manifestación más atroz del totalitarismo" (Revuelta 2014: 4-5).

Retomando el periplo de Félix Saldívar Chacaltana, tras descubrir que el bulto que cargaba su amigo Joaquín al ser asesinado era en realidad el hijo de una desaparecida, su mirada inocente de burócrata anodino y disciplinado experimentará un profundo cambio. De vuelta a Lima, viendo la final por televisión, recordará su paso junto al estadio Monumental de River Plate -“Le había parecido enorme. Más grande que su país" (366)- donde ahora 70.000 hinchas argentinos hacen ondear sus banderas a poco más de dos horas de consagrarse definitivamente como campeones del mundo, proyectando su sombra diez cuadras más allá sobre el edificio de la Escuela Mecánica de la Armada. Chacaltana, por su parte, ya sabe quién es el asesino, sabe también que seguramente acabará matándolo a él, pero no por ello evita acudir a su llamada, como si no pudiera dejar de obedecer igual que ha hecho durante toda su vida. La trama policiaca de La pena máxima se encamina a su conclusión, estamos a punto de conocer el desenlace $y$, por lo que se refiere al fútbol, esto se traduce en este capítulo en una mayor intensidad y frecuencia de los fragmentos dedicados a la crónica del partido. El montaje en paralelo que ha dominado la mayor parte de la novela en un crescendo que hace coincidir la pelea entre los dos antagonistas con los goles decisivos anotados por Argentina en la final. El asesino, antiguo anarquista que se ve obligado a eliminar al traidor de la familia, le confesará entonces, culminando la doble lectura de la metáfora que da título al libro, que "la pena máxima es tener que matar a tu propio hijo" (370). En los televisores y en las radios, el comentarista se acelerará cada vez más y más, mientras "El Matador" Mario Alberto Kempes se acerca al área holandesa bajo la mirada de esos otros "matadores" que presiden el partido desde el palco. La Operación Cóndor, es innegable, alcanzó sus objetivos en el verano de 1978. El asesino anuncia a Chacaltana que lo va a matar, que tan solo está esperando que alguien marque un gol para que la detonación del disparo se pierda entre los gritos de la gente. Kempes anota el primer gol pero, después del 6-0 contra Perú, ya nadie celebra en las calles de Lima los goles de ese equipo que ha humillado a su selección. Si en la primera escena de la novela el fútbol servía para que nadie escuchara los llantos de un bebé, si a lo largo de todo el libro sirve también para ocultar los gritos de los represaliados, finalmente, en una última vuelta de tuerca, se acabará convirtiendo en el motivo de salvación del asistente de archivo Félix Chacaltana:

-Luque engancha para Kempes, peligro por el centro... ¡Gol! ¡Goooooooooool de Argentina!

Si hubiese sido un tanto de Holanda, la reacción habría sido un grito unánime de júbilo en toda la ciudad, un rugido capaz de apagar el disparo de una pistola, o de un cañón. Pero el gol de Argentina fue recibido con un lamento irregular, algunos golpes y, para mala fortuna de Don Gonzalo, un borracho que salió de su casa a ventilar su mal humor. La puerta abierta y las palabrotas ebrias distrajeron la atención del viejo justo el tiempo suficiente para desviar el disparo, que descerrajó el caño produciendo un agudo campanazo. (373-374) 


\section{CONCLUSIONES}

La lista de escritores de novela negra que se han acercado al fútbol durante algún momento de su producción incluye nombres como los de Mankell, Márkaris, Vázquez Montalbán y, más recientemente, Rafael Reig y Santiago Roncagliolo. Todos ellos han descubierto en la alianza entre fútbol y narrativa policiaca una forma de acceder a la corrupción imperante en los grandes centros de poder. Lejos de dejarse seducir por la vertiente épica y sentimental del fútbol, estos autores se centran en describir los mecanismos esencialmente corruptos que rodean a este deporte y que, a medida que se vuelve una industria cada vez más poderosa, han convertido su historia en "un triste viaje del placer al deber" (Galeano 1995: 2). Tal y como hemos podido comprobar en una larga enumeración de obras, la incorporación del fútbol a la novela negra hispánica se consolida como una tendencia editorial durante las primeras décadas del siglo xxI. Ya sea como objeto principal de la trama o bien como marco cronólogico que envuelve los acontecimientos, el balompié descubre su espacio dentro de la voluntad de denuncia social que impulsa a muchos de estos autores. En los casos de Reig y Roncagliolo, la incorporación de la crónica futbolística a una trama ficcional dota de mayor verosimilitud a la narración al mismo tiempo que pone de relieve los elementos de memoria crítica presentes en el género negro. Mientras el escritor español emplea el relato de las victorias de la selección nacional como forma de cuestionar el discurso hegemónico sobre la historia del país, el novelista peruano aborda el horror de los desaparecidos mediante una trama organizada en torno al Mundial de 1978. A través de recursos como equiparar la estructura de sus novelas a la disputa de campeonatos reales, ambos autores denuncian algunas de las formas de represión ejercidas por parte de poderes fácticos que no dudan en recurrir al valor simbólico del fútbol como la "pasión que más dinero mueve en el planeta" (Villoro 2014: 18). Por todo lo dicho hasta aquí, fútbol y novela negra parecen condenados a seguir encontrándose en las sombras que proyectan los estadios.

\section{OBRAS CITADAS}

Alabarces, Pablo (2000): "Los estudios sobre deporte y sociedad: objetos, miradas, agendas". En: Peligro de gol. Estudios sobre deporte y sociedad en América Latina. Buenos Aires, CLACSO, pp. 8-27.

Antezana, Luis H. (1998): "Fútbol y novela negra". En: Un pajarillo llamado "Mané". Notas al pie de su fútbol. La Paz, Plural Editores, pp. 77-97.

Atxaga, Bernardo (2008): El hombre solo. Madrid, Punto de Lectura.

Bromberger, Christian (1999): "El revelador de todas las pasiones". En: Santiago Segurola (ed.): Fútbol y pasiones políticas. Madrid, Debate, pp. 26-36.

Colomer, Juan Carlos (2012): "«Todo está casi perdonado» a propósito de la Transición, debate historiográfico y propuestas metodológicas", Studium. Revista de Humanidades, n. ${ }^{\circ} 18$, pp. 257-272. 
Díaz Arenas, Ángel (1997): Quién es quién en la obra narrativa de Manuel Vázquez Montalbán. Kassel, Reichenberger.

Eco, Umberto (1996): "La cháchara deportiva". En: La estrategia de la ilusión. Barcelona, Lumen, pp. 182-187.

Ferreira, Carlos (2010): "Mundial". En: Francisco J. Uriz (ed.): El gol nuestro de cada día. Madrid, Vaso Roto, p. 97.

Galeano, Eduardo (1995): El fútbol a sol y sombra. Madrid, Siglo xxi.

García Candau, Julián (1996): Épica y lírica del fútbol. Madrid, Alianza.

Izquierdo, José María (2013): "Construcción de la conciencia crítica e hibridación: dos constantes en la obra de Manuel Vázquez Montalbán", Cuadernos de estudios de Manuel Vázquez Montalbán, vol. 1, n. 1, pp. 3-18.

Jara, Maximiliano (2012): Historia del secuestro de una pasión. Santiago de Chile, RIL.

Kohan, Martín (2011): Dos veces junio. Buenos Aires, Debolsillo.

Maristain, Mónica (2012): "Mi novela parece el evangelio de los indignados. Entrevista con Rafael Reig", Página/12, 9 de enero. Disponible en <http://www.pagina12. com.ar/diario/suplementos/espectaculos/4-24025-2012-01-10.html> [última visita: 15.04.2015].

Márkaris, Petros (2011): Con el agua al cuello. Barcelona, Tusquets.

Mena, Miguel (2006): Días sin tregua. Barcelona, Destino.

Noguerol, Francisca (2006): "Neopolicial latinoamericano: el triunfo del asesino", Ciberletras: Revista de crítica literaria y de cultura, n. ${ }^{\circ} 15$. Disponible en <http://www.lehman.edu/faculty/guinazu/ciberletras/v15/noguerol.htm> [última visita: 30.03.2015].

Olguín, Sergio (2008): Lanús. Barcelona, Tusquets.

Padilla, Toni (2013): "Videla y el Mundial'78: no solo fue culpa de Argentina", Panenka. El fútbol que se lee, 17 de mayo. Disponible en <http://www.panenka.org/reportajes/videla-y-el-mundial78-no-solo-fue-culpa-de-argentina/> [última visita: 4.04.2015].

Pardo, Pedro Javier (2010): "Teoría y práctica de la reescritura filmoliteraria". En: José Antonio Pérez Bowie (ed.): Reescrituras fílmicas: nuevos territorios de la adaptación. Salamanca, Universidad de Salamanca, pp. 45-102.

Pérez, Leandro (2014): Las cuatro torres. Barcelona, Planeta.

Perilli, Carmen (2010): "Todas las sangres. La narrativa peruana de posguerra", Telar. Revista del Instituto Interdisciplinario de Estudios Latinoamericanos, n. ${ }^{0}$ 7-8, pp. 76-91.

Reig, Rafael (2011): Todo está perdonado. Barcelona, Tusquets.

Revuelta, Laura (2014): "La literatura se olvidó del fútbol. Ahora hemos salido del armario. Entrevista con Santiago Roncagliolo", ABC Cultural, 10 de mayo, pp. 4-6.

Roncagliolo, Santiago (2014): La pena máxima. Madrid, Alfaguara.

Ros, Violeta (2013): "Representaciones de la transición española en la novela actual: una indagación en la configuración de la cultura democrática", Olivar, vol. 14, n. ${ }^{\circ} 20$, pp. 149-169.

Sacheri, Eduardo (2014): "Los malditos", El Gráfico, n. ${ }^{\circ}$ 4452. Disponible en <http://www. elgrafico.com.ar/2014/12/14/C-5860-los-malditos-un-texto-de-eduardo-sacheri. php> [última visita: 10.04.2015]. 
Salinas, Alexander (2007): "Novela negra y memoria en Latinoamérica", Poligramas. Revista literaria, n. ${ }^{\circ}$ 27. Disponible en <http://poligramas.univalle.edu.co/27/NOVELA\%20NEGRA\%20Y\%20MEMORIA\%20EN\%20LATINOAMERICA.pdf> [última visita: 10.04.2015].

Savater, Fernando (1983): La tarea del héroe. Madrid, Taurus.

Silva Romero, Ricardo (2009): Autogol. Bogotá, Alfaguara.

Vázquez Montalbán (1988): El delantero centro fue asesinado al atardecer. Barcelona, Planeta.

(2005): Fútbol. Una religión en busca de un Dios. Barcelona, Debate.

Verdú, Vicente (1980): El fútbol: mitos, ritos y símbolos. Madrid, Alianza.

(2010): "La exultación y el azar", Revista de Occidente, n. 351, pp. 5-9.

Villoro, Juan (2006): Dios es redondo. Barcelona, Anagrama.

- (2014): Balón dividido. México, Planeta. 